\title{
Línguas, culturas literárias e culturas políticas na modernidade goesa*
}

\author{
Languages, literary cultures and political cultures \\ in Goan modernity
}

\section{Sandra Ataíde Lobo*}

Resumo: Este ensaio explora o conceito de cultura literária e o seu lugar na formação de culturas políticas. Nele defendo o interesse teórico e metodológico, para a história intelectual, de uma ideia abrangente do conceito de cultura literária. Aplicando a proposta ao caso goês no período colonial, refiro o multilinguismo e a importância de atender à história social, política e intelectual de cada língua na formação de culturas literárias locais diversas. Coloca-se o desafio de estudar essa diversidade, os trânsitos entre tradições e o uso político-cultural da paleta das línguas, atendendo à coexistência do multilinguismo com o plurilinguismo nesta sociedade.

Palavras-chaves: Culturas literárias, culturas políticas, história intelectual de Goa, multilinguismo, plurilinguismo

\begin{abstract}
This essay explores the concept of literary culture and its place in the creation of political cultures. In this text I defend the theoretical and methodological interest, for intellectual history, of adopting a broad idea of the concept of literary culture. Focusing the Goan case in the colonial period, I recall its multilingualism and the importance of attending the social, political history and intellectual history of each language in the constitution of diverse local literary cultures. The challenge is to study such diversity, the transits between traditions and the political-cultural use of the palette of languages, considering the coexistence of multilingualism with plurilingualism in this society.
\end{abstract}

Keywords: Literary cultures, political cultures, intellectual history of Goa, multilingualism, plurilingualism

\footnotetext{
Texto oriundo do Projeto Temático "Pensando Goa", da Fundação de Amparo à Pesquisa do Estado de São Paulo (número de processo: 2014/15657-8).

** Doutora em História e Teoria das Ideias pela Universidade Nova de Lisboa. Investigadora integrada do CHAM - Centro de História d'Aquém e d'Além-Mar. Bolsista de Pós-Doutoramento financiada pela Fundação para a Ciência e Tecnologia.
} 


\section{1. conceito e as ideias de literatura}

Raymond Williams, na influente obra Culture and society (1958), dedicada à história da moderna ideia de cultura na língua inglesa, na Inglaterra do século 18, aborda mudanças capitais no léxico e na semântica desta língua desde o ocaso desse século. Mudanças que, respondendo a um mundo em rápida transformação, contribuíram para modelar e criar uma nova mundividência. Williams comprova como as mudanças semânticas/conceptuais na língua inglesa incluíram a ideia de arte, deslocando-a da referência plural e genérica a competências/habilidades humanas diversas para um corpo de actividades criativas ou imaginativas. Agrupadas pela característica criativa, essas artes, ou categorias artísticas, podiam por isso mesmo ser vistas como distintas das outras especialidades humanas. Cabe recordar que, pela mesma altura, Hegel fundava a estética como filosofia da arte.

A ideia de literatura tal como se afirmou entre os séculos 18 e 19, associada à escrita criativa e seus géneros, inscreveu-se neste movimento que o intelectual britânico acompanha em Marxism and literature (1977). Williams evidencia como até essa época o foco da ideia de literatura fora a leitura, reportando-se, com o desenvolvimento da imprensa, à leitura do impresso (WILLIAMS, 1977, p. 46 ss.). No contexto da emergência e expansão do impresso a partir do século 16 , a qualidade do leitor tinha-se imposto como marcador social, distinguindo uma capacidade largamente associada ao domínio das línguas clássicas europeias e ao humanismo universalista. Por extensão, a literatura passara a poder reportar aos livros impressos, suportes da configuração dessa literacia humanista. Em qualquer dos casos incluía todo o género de livros impressos, já que literatura traduzia primordialmente a capacidade e experiência de leitura "educada" e "humana".

Sobretudo a partir do movimento romântico, terá ocorrido um deslocamento para o foco na obra e no ato criador e para a nacionalização da literatura. Tal deslocamento é associado por Williams a três tendências distintas: 1 . a mudança, na avaliação da qualidade da cultura literária, da ideia de aprendizagem para a de "gosto" ou "sensibilidade"; 2 . a especialização da literatura como respeitante à obra "criativa" ou "imaginativa"; 3. o desenvolvimento do conceito de tradição em termos nacionais, promovendo a definição de literaturas nacionais vernáculas (WILLIAMS, 1977, p. 48). 
Parametrizada pela nova disciplina da crítica literária, que passou a ocupar-se da definição dos valores literários e das fronteiras da literatura, a constituição de literaturas nacionais compreenderia a delimitação de um corpus literário que as objetivavam. Concebidas como tradição literária vernácula em aberto, seriam avaliadas tanto pela sua originalidade coletiva na expressão da identidade nacional, quanto pela criatividade dos autores e qualidades estéticas das suas obras em expressar a sua diferença, o seu contributo à construção de um património literário comum. Partindo deste ponto de vista, em que a originalidade se constituiria como marcador fundamental de identificação das literaturas nacionais, colocar-se-ia o problema de saber quais as nações que, contando embora com escritores vernáculos, podiam reivindicar ou viam reconhecido um património literário. Mais, como interpretar tradições em línguas não vernáculas, quando se firmava a ideia de que só na língua em que fora embalado, guardiã do código genético da cultura de cada povo, poderia o escritor expressar a sua sensibilidade e originalidade em termos esteticamente relevantes?

Em 2011, Carlos Manuel Ferreira da Cunha publicou um ensaio relevante dedicado às Geografias da literatura, onde revisita a história da literatura nos seus aspetos teóricos e confronta as aporias que presentemente marcam a conceção da literatura no contexto global e pós-colonial. Nele recorda-nos como a moderna conceptualização das literaturas nacionais pelo Norte europeu determinou a perceção da produção literária de outras geografias e por outras geografias, do Sul europeu e outros continentes. A ideia de literatura aplicada a contextos locais concretos transportaria uma dimensão instituidora exigindo processos de validação por critérios não autónomos, primariamente configurados pelo Norte e que apoiariam a sua hegemonia cultural e aspiração universalizante. Nesse quadro, Cunha refere à indecisão por longo tempo mantida sobre a existência de uma literatura portuguesa. E também como a associação patrimonial entre nação e língua vernácula terão constrangido tanto a admissão de um plurilinguismo literário em quadros nacionais, quanto de uma partilha linguística por diferentes geografias literárias sem que se erguessem questões patrimoniais. Os decorrentes problemas de menorização, podendo contribuir para bloqueios criativos, sentir-se-iam de forma particularmente gravosa em contexto colonial. 


\section{A ideia de literatura em contexto colonial: o caso goês}

O caso goês é significativo, sendo de notar a obra Literatura indo-portuguesa de Vicente de Bragança Cunha, um dos primeiros esforços locais de delimitação dessa literatura, que repescava em 1926 um conjunto de artigos que publicara no jornal $A$ Índia Portuguesa, quando fora seu diretor. Ainda não chegado a meio da obra, na qual as dificuldades analíticas e narrativas se evidenciam, o intelectual abdicava de oferecer um panorama dessa literatura ou de teorizá-la. Em alternativa, dedicar-se-ia a alguns aspetos da história cultural e política local e à reflexão sobre a situação goesa no contexto do nacionalismo indiano. Tal volte-face não pode ser desligada da sua avaliação da produção conterrânea, que expressou em A Índia Portuguesa, embora sem reproduzir no livro. Na sua opinião, a literatura da Índia Portuguesa seria "um mero prolongamento da literatura da metrópole", devido ao continuado empenho da população católica em integrar o imaginário da portugalidade (CUNHA, 1919).

Já no ocaso do domínio português, o padre Filinto Cristo Dias publicaria no Boletim Eclesiástico da Arquidiocese de Goa (1957-1961) um estudo dedicado à literatura indo-portuguesa, sobretudo escrita em português como já tinha sido o caso de Bragança Cunha, que depois editou em volume próprio (1963). Ao inaugurar a publicação no boletim, o autor afirmava não ter condições para traçar uma história da cultura literária indo-portuguesa por falta de tradição local de investigação sistemática "das vicissitudes da nossa cultura, as influências mesológicas e as que foram exercidas pelo meio exterior sobre os nossos escritores" (DIAS, 1957, p. 233). Isto é, o Padre Dias apontava uma ideia de cultura literária, construída na confluência do impacto nos escritores indo-portugueses do meio ambiente cultural local e das influências externas. Impossibilitado de concretizar tal ambição, propunha-se esboçar, recorrendo a materiais dispersos, uma História da literatura indo-portuguesa. A história do padre Dias era, na verdade, um levantamento de autores e obras que adotava um sentido lato do conceito de literatura, não cingido ao sentido de escrita criativa que vimos apontado por Raymond Williams.

Este entendimento lato, aliado à ambição catalográfica, foi assumido por Aleixo Manuel da Costa, o primeiro estudioso goês a cunhar o conceito de literatura goesa no título de uma obra (COSTA, 1967). A ambição de cartografar todos os autores goeses que tivessem publicado, até 1961, livros ou folhetos em portu- 
guês, inglês ou concani foi levada por Aleixo Costa ao ponto de incluir no Dicionário de literatura goesa (1997-2013) pessoas que unicamente publicaram pleitos judiciais. $\mathrm{O}$ facto de associar a ideia de autores goeses a quem publicou nas referidas línguas e tipologia de publicações explica as significativas omissões de autores, designadamente mulheres e hindus, que só publicaram em jornais e revistas ou em marata. Por outro lado, apesar de o seu dicionário procurar um inventário exaustivo da imprensa periódica, nota-se um claro menor investimento na imprensa nacionalista publicada no exílio a partir da independência da Índia (cf. LOBO, 2013, Introdução aos Anexos).

A parceria Vimala Devi/Manuel de Seabra também adotou uma aceção abrangente de literatura, sobretudo pela dificuldade em conciliar uma teorização construída em torno da literatura europeia com o panorama local. ${ }^{1}$ Tomando o modelo europeu como paradigma, foram os primeiros estudiosos a preocupar-se com as fronteiras da literatura e dos géneros literários locais. Perante esse modelo confessavam a dificuldade em "arrumar" autores e obras uma vez que entendiam que "entre os escritores goeses nunca houve, bem definida, uma consciência de géneros literários como na Europa" (DEVI; SEABRA, 1971, p. 237). Designadamente tornava-se difícil delimitar as fronteiras "entre ensaio, crítica literária, historiografia e religião (ensaio de tema religioso)" (ibidem). ${ }^{2}$ Tais dificuldades e a opção de, ainda assim, adotar o guião desse modelo levaria a que incluíssem no género ensaístico um larguíssimo espectro de textos da mais diversa natureza e diversos fins, sem que esclarecessem por que outros textos similares eram arrumados nos capítulos dedicados a obras religiosas, à linguística, à historiografia, às ciências auxiliares da história, ao jornalismo.

\footnotetext{
1 Agradeço a Cielo Griselda Festino ter chamado a minha atenção para este facto numa leitura crítica da primeira versão deste ensaio.

2 Ainda discutindo esta questão, Hélder Garmes, em outra leitura crítica deste ensaio, defendeu o uso informado que os escritores goeses fariam desses géneros, deles fazendo um "uso peculiar". 0 problema de Devi e Seabra resultaria, assim, por um lado de sugerirem ignorância goesa das teorias europeias e, por outro lado, de esquecerem que mesmo na Europa eles foram constantemente desafiados, designadamente pelo Romantismo, em cujas propostas fundamentais contava-se a mistura de géneros.
} 
Na verdade, a sua obra resultou no primeiro ensaio de construção de uma história cultural goesa ${ }^{3}$ e de delimitação da identidade goesa por essa via, substancialmente associada à comunidade católica. Essa história serviu de guião à abordagem da história literária indo-portuguesa, sobretudo atenta à produção escrita em língua portuguesa, embora também, e pela primeira vez de forma significativa, acompanhando brevemente a literatura em concani e marata. Foram os primeiros autores a desenvolver um esforço consistente de crítica das obras mais relevantes de cada género. Foram eles que também pela primeira vez chamaram a atenção para o manancial da imprensa periódica quer para abordar a constituição dos gostos locais, quer para descobrir e refletir sobre o lugar do conto e da poesia na produção literária goesa.

Não é claro que qualquer dos investigadores citados se tenha proposto recuperar um entendimento humanista de literatura, isto é, um entendimento transdisciplinar não estritamente associado à criação literária, tal como apontámos no início deste ensaio. Tendo, no entanto, abordado sobretudo a produção de expressão portuguesa, se se cingissem ao seu entendimento como escrita criativa delimitado pelo cânone europeu, seriam obrigados a oferecer um panorama muito mais magro dessa produção. A flexibilização desse cânone permitiu-lhes evidenciar uma significativa tradição intelectual goesa em língua portuguesa liderada pelas elites católicas nativas, tendo a partir de meados do século 19 surgido um relevante conjunto de autores e um movimento editorial significativo, nos mais diversos campos.

A opção destes estudiosos garantiu que ainda hoje as suas obras constituam instrumentos de iniciação imprescindível a qualquer abordagem da cultura goesa de expressão portuguesa. No entanto, não permitiu ultrapassar a indefinição local sobre a existência de uma literatura goesa, ou mesmo de uma tradição intelectual goesa significativa. Tal indefinição parece manter-se, apesar do papel da Universidade de Goa e de algumas instituições de ensino e culturais goesas em favor do (re)conhecimento das literaturas nas línguas vernáculas goesas (marati e concani), bem como em inglês e português. Sobretudo, verifica-se a falta de

3 Como mais uma vez Festino me fez questionar, estes autores mostravam-se pouco atentos aos caminhos abertos pelos Cultural Studies, que abriram a discussão sobre as fronteiras da literatura e sobre os silêncios impostos pelas elites responsáveis pelo estabelecimento dos cânones literários, em cujo impulso Raymond Williams esteve particularmente envolvido. 
investimento consistente em fazer dialogar as diversas tradições, e, consequentemente, em reconhecer esse multilinguismo literário como valor patrimonial. É de assinalar que não existe qualquer obra que adote tal perspetiva, escasseando também títulos de fôlego dedicados a qualquer destas expressões literárias.

No que respeita ao conhecimento da literatura em português e à sua relação com as tradições literárias em outras línguas, tem concorrido o corte local com essa língua após a integração de Goa na União Indiana, quando até 1961 dominaram as publicações de autores goeses, embora não de forma exclusiva, como vimos. Tal limitação linguística constitui um obstáculo à sua frequência e ao reconhecimento patrimonial de tal produção. De qualquer forma, na perceção pública local parece firmada a ideia de inexistência de um corpo significativo de literatura goesa (criativa ou outra) em língua portuguesa a que valha a pena atender. Entre os obstáculos à sua recuperação conta-se o carácter editorialmente fragmentado dessa produção, geograficamente disperso e consideravelmente espraiado em jornais e revistas, exigindo um esforço compilador que se pode verificar ingrato num momento em que as poucas coleções sobreviventes se encontram em avançado estado de degradação física.

A recente publicação da tese de 1995 de Fr. Eufemiano de Miranda constitui uma das raras afirmações editoriais locais na atualidade de uma tradição de literatura criativa goesa em português. No entanto, evidencia como o contexto colonial dessa produção se revela pesado à sua interpretação pós-colonial, designadamente na determinação de quem e que tipo de obras poderão integrar tal projeto. Apesar do título adotado na versão publicada em 2012, que significativamente, embora escrito em português, tem o título bilingue Oriente e ocidente na literatura goesa = East and West in Goan literature, os diálogos entre Oriente e Ocidente procurados pelo autor são os que encontra na literatura goesa produzida por um tipo de escritor. Sendo este o indo-português que, de acordo com a definição de Ethel Pope que Eufemiano de Miranda adota, reporta aos "escritores etnicamente indianos de Goa que, estando 'imbuídos pela cultura ocidental, ficaram também influenciados pelo pensamento e atmosfera oriental'"' (MIRANDA, 2012, p. 16).

Miranda chega a estabelecer um cânone para essa literatura quando faz equivaler as noções de "literatura indo-portuguesa" e "literatura goesa de expressão portuguesa". Querendo "goesa" significar as "pessoas etnicamente indianas de Goa que tiveram domínio perfeito da língua portuguesa e trataram de temas 
goeses ou, de qualquer modo, indianos" (ibidem, p. 17). Nesse sentido, esse cânone apresenta-se como uma metáfora da identidade goesa. Se a circunscrição étnica o leva a excluir os escritores luso-descendentes, a cultural obriga-o a afastar as obras que desestabilizem o perfil a fixar.

Apesar de Eufemiano de Miranda convocar alguns autores hindus, na sua obra o escritor indo-português configura-se como dominantemente católico em termos quantitativos, culturais e psicológicos. No entanto, apesar de católico e aparentemente ocidentalizado, o indo-português na verdade define-se como essencialmente hindu, sendo o hinduísmo identificado como marcador da verdadeira indianidade. ${ }^{4} \mathrm{~A}$ sua leitura merece ser citada:

[É ele] um homem sob o signo duma ruptura. Etnicamente indiano ele é uma pessoa que em virtude, de um lado, da cultura cristã e ocidental que assimilou, e, do outro, dum fortíssimo subconsciente do substrato upanixádico-vedântico, hindu que o domina, se volta para si mesmo, de uma maneira dolorosa e dramática, à maneira dos românticos, no desejo de saber quem é, no desejo de se definir (ibidem, p. 310-311).

O catolicismo e a ocidentalização apresentam-se, assim, como roupagens artificiais e estéreis que o deixam desconfortável, impulsionando-o a recuperar a sua identidade verdadeira no labirinto do seu subconsciente, única possibilidade de criatividade e originalidade. Nesse processo inconsciente, o escritor indo-português: "salvo raríssimas exceções definiu-se como um indiano autêntico, telúrico, de expressão portuguesa. Um deslumbrado de luz da arte literária

\footnotetext{
4 O processo de essencialização da identidade indiana na "identidade hindu" e de fixação desta mesma identidade tem sido bastante estudado e discutido, designadamente pelas suas repercussões político-culturais no processo democrático indiano. Esse processo hegemónico marcou e continua a marcar o intenso debate sobre a identidade goesa, centrado no confronto entre as chamadas "Goa portuguesa" e "Goa índica", clichês que resumem a divergência sobre o resultado sociocultural de cerca de 450 anos de domínio português das chamadas "Velhas Conquistas" e de sensivelmente dois séculos das Novas Conquistas. No que respeita à população católica discute-se a "profundidade" e extensão social dos processos de cristianização e de "assimilação" da cultura portuguesa, e, consequentemente, grau de divórcio das suas raízes indianas (hindus), tendendo a assumir-se a quase impermeabilidade cultural hindu ao domínio português. Estes clichês vêm sendo ultimamente questionados, designadamente por investigadores que propõem outros para abordar as questões de identidade político-cultural. Veja-se a recente tese de doutoramento de Jason Keith Fernandes, a qual coloca a discussão num novo patamar teórico (FERNANDES, 2013).
} 
portuguesa, ele fundamenta a sua originalidade na força inspiracional indiana" (ibidem, p. 311).

A língua portuguesa apresenta-se assim como simples meio de expressão, mantida à superfície do modo de pensar e sem tocar o sentir deste impermeável indo-português. Como tal, revela-se a um tempo a expressão máxima do projeto assimilacionista português e o testemunho maior do seu falhanço.

No entanto, nos últimos anos tem-se assistido a um movimento de afirmação académica internacional de literatura criativa goesa em língua portuguesa, contando com importantes trabalhos académicos que abrem caminho a abordagens multidisciplinares e comparatistas tanto no âmbito de outras literaturas em língua portuguesa, como de outras literaturas indianas em outras línguas.

\section{Cultura literária e culturas literárias: escrita, leitura e trânsitos intelectuais}

No quadro do conceito de culturas literárias que procuro explorar, cabe recordar que a definição da literatura como escrita criativa não apagou, antes ampliou, a sua ligação ao impresso que até recentemente se manteve como meio soberano de divulgação. Em outros termos, não apagou a relação, umbilical na modernidade, entre produção literária e um amplo público leitor. Assim sendo, a receção e o impacto tornaram-se significativos na ponderação do valor e da relevância coeva e futura das obras, e do seu lugar na construção de tradições literárias. São estes referentes, obra e leitura, que têm marcado o conceito de cultura literária, o qual respeita tanto à consolidação de literaturas como de leitores específicos.

O conceito de cultura literária é, assim, abundantemente usado para referir tradições literárias nacionais concretas e o seu papel na consolidação das respetivas culturas. É igualmente usado para reportar à formação literária do leitor, ou seja, o que lê e o que deve ler. Nesta aceção frequentemente surge associada ao desiderato de aquisição de uma boa ou vasta cultura literária. Tem sido por isso objeto de particular atenção de educadores e pedagogos, pois sendo certo que a presente ideia de literatura a afastou dos objetivos que informam a constituição dos saberes científicos e a aquisição de uma cultura científica, a literatura, como escrita criativa, continua a ver reconhecido um relevante papel formativo em outros campos, designadamente na configuração dos gostos, sentimentos e 
sensibilidade, valores humanos, sociais, culturais, políticos, identitários de sinal diverso, enfim na modelação de visões do mundo, bem como de crítica e conformação social.

Não é tanto por estas razões que Richard Rorty reservou um lugar central na sua filosofia política ao conceito de cultura literária, mas pela potencialidade expansiva da literatura na imaginação das possibilidades de ser humano. Rorty foi ao ponto de defender, no ensaio The decline of redemptive truth and the rise of a literary culture (2000), que os últimos dois séculos foram de afirmação da literatura entendida como escrita criativa, vindo a ocupar o lugar na configuração da cultura antes ocupado primeiro pela religião e depois pela filosofia.

As I am using the terms "literature" and "literary culture", a culture which has substituted literature for both religion and philosophy finds redemption neither in a non-cognitive relation to a non-human person nor in a cognitive relation to propositions, but in non-cognitive relations to other human beings, relations mediated by human artifacts such as books and buildings, paintings and songs. These artifacts provide glimpses of alternative ways of being human. This sort of culture drops a presupposition common to religion and philosophy - that redemption must come from one's relation to something that is not just one more human creation (RORTY, 2000, p. 7).

São estes artefactos, com particular destaque para a literatura, que "fornecem vislumbres de modos alternativos de ser humano." Na utopia democrática de Rorty, assumidamente influenciada por Oscar Wilde, o papel do "intelectual literário" será precisamente o de abrir o leque de possibilidades de ser humano, promovendo uma cultura de tolerância a qual, a par da postura cooperativa, constitui o ponto nodal de afirmação de uma sociedade democrática, onde cada um viva a vida como prefere reconhecendo aos outros igual direito.

Mesmo sem conferir essa carga utópica ao conceito de cultura literária, o reconhecimento das potencialidades da literatura na sedimentação, por empatia, de sentimentos e ideias, tem conduzido sucessivas gerações de intelectuais a reservar um lugar importante à criatividade literária na promoção de movimentos culturais e políticos. Recordo, a esse propósito, o intelectual goês Adeodato Barreto em carta ao médico e ensaísta António Aleixo Santana Rodrigues, escrita em princípios de 1927 e que se encontra no seu espólio à guarda do filho Kalidas 
Barreto. Nessa carta o intelectual discorria sobre a necessidade de criar uma literatura goesa que se insinuasse no espírito dos leitores "até mesmo contra a sua vontade" com vista a "ensinar os goanos a amar a Índia". Ele próprio dedicaria a esse projeto, principalmente através dos géneros poético e ensaístico, alguma da sua melhor escrita.

Não pretendo discutir a autonomia e relevância da literatura criativa, deixando a discussão das suas fronteiras para os especialistas. Defendo, no entanto, que a história intelectual será beneficiada por uma aceção abrangente do conceito de cultura literária que atenda à relação entre a escrita e a leitura e recupere a perspetiva transdisciplinar da ideia de literatura de cariz humanista. Sobressaem as evidentes relações, edificadas sobre trânsitos intelectuais e perplexidades comuns, da escrita criativa com outras escritas associadas às humanidades e às disciplinas que estudam e refletem sobre a condição humana nas suas dimensões individual e coletiva. Contam as próprias relações estilísticas a ponto de as fronteiras poderem evidenciar-se ténues, como no caso do ensaísmo ou da própria escrita da história. No último caso, convocamos o conceito de "imaginação histórica" cunhado por Collingwood (1946), de evidente dimensão epistemológica.

Pensada nessa perspetiva transdisciplinar e não canónica, mas atenta à crescente "disciplinarização" do pensamento e da escrita na modernidade, a ideia de cultura literária, ou antes de culturas literárias coexistentes no tempo e no espaço, que aponto sugere modos próprios de conceber, produzir, fazer circular e interpretar ideias, ideais e valores. Isto é, reporta a culturas de comunicação escrita e de leitura, cultivadas num leque alargado e crescente de línguas, que na modernidade tiveram no ensino e na imprensa os instrumentos fundamentais de derramamento social. São abordáveis como constelações intelectuais dinâmicas e actividades intelectuais constitucionalmente ligadas ao mundo da escrita, simultaneamente abertas e exclusivas. Constelações essas sustentadas pelas actividades de criação e expressão, disseminação e receção, crítica e debate, de ideias, valores, saberes, crenças, memórias, sentimentos. E, ainda, pelo exercício de aproximar e constituir a realidade coletiva através da análise, consagração, denúncia e propostas de transformação. Enquanto constelações abertas e exclusivas, nas quais a língua ou línguas de cultivo e de convívio ocupam um lugar central, importam as formas de relacionamento com o passado/presente literário próprio e de outras culturas. 


\section{Culturas literárias e culturas políticas em contexto colonial: o caso goês}

Aplicada esta abordagem a sociedades sujeitas na modernidade ao domínio colonial europeu nas quais por norma coexistiram diversas línguas orais e literárias, há que observar como a hierarquização funcional das línguas tendeu a confirmar a hierarquia das relações coloniais e, eventualmente, a reproduzir ou mesmo contribuir para configurar tensões internas. Ao abordar a problemática das línguas na configuração das culturas literárias destas sociedades, cabe estar atento às atitudes dos Estados Colonialistas de proteção, indiferença, perseguição ou de controlo ideológico das línguas literárias nativas, permitindo ou comprometendo a sua sobrevivência ou mesmo incentivando a sua emergência.

Por outro lado, tem merecido crescente atenção as relações estabelecidas pelas comunidades e grupos sociais colonizados com a língua do poder, a sua militância na afirmação das línguas nativas, e, ainda, a forma como jogaram com a paleta de línguas disponíveis no desenvolvimento de estratégias de identificação e de resistência cultural e política. Neste quadro verifica-se particularmente produtiva a aproximação ao papel do plurilinguismo literário na promoção de trânsitos culturais e políticos, reflectidos no léxico e na semântica, mas também nas temáticas e tipologias de textos. Num campo de investigação mais delicada, a avaliação da disseminação social das culturas literárias pode e tem todo o interesse em abrir-se às relações com as culturas orais.

Decorre desta formulação as relações potenciais com a sedimentação de culturas políticas específicas, entendidas como modos de estar na política e de pensar as suas ideias, valores e fins. A abordagem que venho publicando da realidade política e cultural goesa tem abarcado o processo de afirmação do quadro político liberal e de emergência dos valores democráticos, desde a Revolução de 1820 e até final da Primeira República portuguesa. Entre os aspetos marcantes da política portuguesa deste período, conta-se a afirmação constitucional da conceção provincial dos espaços ultramarinos e a extensão dos direitos civis e políticos de cidadania aos seus habitantes. Não pretendo discorrer sobre as suas nebulosidades e contradições (SILVA, 2009; LOBO, 2013). Antes destaco como as populações colonizadas, sobretudo as elites intelectuais e políticas que tenderam a monopolizar o discurso nativo na esfera pública, puderam refletir sobre a (e se beneficiar da) nova conceção da política como domínio da cidadania. Para isso contavam com mecanismos participativos próprios, os quais na prática esti- 
veram sujeitos a processos desiguais dependendo das realidades locais e da sua capacidade interventiva.

Sobressai no caso goês o precoce envolvimento das elites católicas nativas no processo político liberal. Bernardo Peres da Silva constitui o caso mais notável desse envolvimento. Após a Revolução de 1820 integrou, ao lado de Constâncio Roque da Costa, o único conjunto de deputados predominantemente nativos de um domínio português eleitos às Cortes Constituintes. Com a queda da Carta Constitucional, outorgada a Portugal por D. Pedro IV de Portugal e I do Brasil, escolheu o exílio no Brasil após uma breve passagem por Inglaterra. Esse envolvimento e a sua visão política foram reconhecidos por $\mathrm{D}$. Pedro que, em vésperas de falecer, o nomeou Prefeito do Estado da Índia. Este constituiria o único caso na história do império português desde 1820 até ao fim do império de um nativo de um espaço colonial ser nomeado para dirigir os destinos desse espaço.

Importa aqui que Peres da Silva, apesar de não ser um autor prolixo, ter deixado alguns textos publicados e inéditos politicamente relevantes. $\mathrm{O}$ mais importante foi escrito quando esteve exilado no Rio de Janeiro. Publicado nessa cidade em 1832, o seu Diálogo entre um doutor em filosofia e um português da Índia constitui a primeira obra política publicada por um nativo goês. Nesta pequena obra, o político interpretava o constitucionalismo cartista e as suas consequências locais. Mais do que isso, questionava as relações entre liberalismo e colonialismo. De acordo com a sua leitura, a sobrevivência de práticas políticas não liberais, correntes nos domínios coloniais, era incompatível com espaços políticos que se quisessem defensores dos valores liberais. Isto é, sem questionar a sobrevivência de estados liberais transcontinentais, fazia depender a sua legitimidade da afirmação do princípio da cidadania transcontinental e do aprofundamento da coesão política, social e económica entre os espaços.

Este e outros textos do político goês evidenciam uma cultura política "literária" permitida pelo seu domínio do português e do francês, e provavelmente do inglês, havendo que recordar que parte da sua vida adulta foi vivida com a presença do exército inglês em Goa e que a imprensa de língua inglesa publicada em Bombaim e Calcutá provavelmente chegava ao território. Isto é, estes textos testemunham a leitura de autores significativos do pensamento liberal francês e britânico. Estas leituras e certamente os diálogos estabelecidos nos círculos que frequentou em Goa, e posteriormente em Portugal, Inglaterra e Brasil, serviram para consolidar um pensamento próprio. 
Há que notar que o Diálogo foi referido por Christopher Bayly, designadamente em Recovering liberties, para testemunhar, a par dos escritos do intelectual indiano Rammohan Roy, ${ }^{5}$ uma precoce corrente constitucional liberal na Ásia. Citando Bayly:

os confrontos políticos e militares coevos entre a "internacional liberal" e a "aliança do despotismo" ajudaram a conferir sentido ideológico a lutas mais paroquiais entre os britânicos, indo-portugueses ou mercadores e intelligentsia indiana, na medida em que lutavam por representação e influência contra o monopólio e diktat oficial através da Ásia (BAYLY, 2011, p. 46).

Peres da Silva, tal como Rammohan Roy, revela uma leitura dinâmica do pensamento liberal europeu e atenção ao panorama geopolítico coevo ao construir a sua grelha de análise política. $\mathrm{O}$ goês aplicá-la-ia à crítica dos colonialismos português e britânico na Índia e ao equacionamento de expectativas e responsabilidades locais na sedimentação de uma cultura política liberal. Um e outro pensador participaram ativamente na edificação de uma cultura política liberal na Índia, estando ainda por reconhecer o seu lugar intelectual no pensamento liberal em termos mais globais.

Fizeram-no recorrendo ao meio considerado mais eficaz para a sua disseminação, a escrita destinada a ser lida, reproduzida e comentada através da imprensa. Ao fazê-lo participavam da construção de culturas políticas literárias locais, o goês em língua portuguesa e o bengalês, evidenciando o seu poliglotismo literário, em inglês, bengali, hindi, persa e sânscrito. Enriqueceram-nas, ainda, com a divulgação de pensadores ingleses e franceses influentes na construção coeva da "internacional liberal", tomando de empréstimo a ideia de Bayly.

Subjaz ao discurso educativo de Peres da Silva, neste e sobretudo em outros textos, a atenção à literacia em português e em outras línguas europeias, bem

5 Rammonhan Roy (1772-1833) foi um intelectual bengalês interessado no movimento liberal, tendo acompanhado de perto a onda revolucionária das primeiras décadas do século 19. Liderou o movimento de reflexão sobre as consequências destas novas ideias na Índia e sobre o processo de afirmação do domínio inglês no território. No plano religioso e social teve um papel reformista essencial, tendo liderado a fundação do Brahmo Sabha, que deu origem ao Brahmo Samaj, fundamental na chamada Renascença Bengali, da qual Rabindranath Tagore foi considerado o último grande representante. 
como à formação avançada na Índia e na Europa, com o fim de aliar os conhecimentos disciplinares e práticos à exposição "a essa educação que se chama do mundo" (SILVA, 1832, p. 41). Com tal projeto visava criar um escol com capacidade crítica para intervir na Índia e em Portugal, mormente através da imprensa, na formação de uma opinião pública e na defesa dos direitos locais.

Como tem sido destacado, a precocidade e visibilidade da escrita política e cultural das elites católicas goesas, quando comparada com a situação em outros espaços do império português, e a eficácia do seu ativismo na constituição de uma esfera pública local são devedoras do largo investimento, herdado dos séculos anteriores mas expandido no século 19, na educação em português, beneficiando da proteção oferecida pelo Estado colonialista à língua e à sua afirmação social. A proficiência na língua do poder permitiria que dominassem, e particamente monopolizassem até finais do século 19, a interlocução nativa com o poder e os discursos políticos, culturais e identitários locais. Nesse processo de afirmação confiaram largamente na consagração de uma cultura literária local, investindo consideráveis esforços na afirmação de uma imprensa, designadamente periódica, que Ihe servisse de veículo. Uma abordagem estatística das publicações de autores goeses que iniciaram a sua atividade até 1933 , baseada no Dicionário de literatura goesa de Aleixo Costa, revela que as principais áreas de investimento foram, para além da consagração de uma cultura católica, o domínio político, da história local e da criação literária (LOBO, 2013, Anexos). Em qualquer destes domínios o foco na realidade goesa surge evidente.

Por contraste, a significativa comunidade hindu goesa permaneceria sobretudo ligada à afirmação da esfera do marata, apesar de, no século 20 sobretudo, ter emergido um segmento das suas elites literariamente bilingue em português e marata. Este grupo lograria intermediar as relações entre as comunidades, hindu e católica, e dominar a produção de discursos em língua portuguesa sobre a condição e aspirações hindus, chamando a si a representação da indianidade no ambiente hostil de hegemonia da cultura portuguesa. Urge, no entanto, questionar em que medida a cultura literária goesa marata revela impermeabilidade às fontes intelectuais que circulavam neste espaço colonial, através da língua portuguesa. Por outro lado, cumpre interrogar se a aparente impermeabilidade à cultura literária portuguesa traduz um fechamento a diálogos intelectuais com quaisquer correntes de pensamento europeu, ou tenderá a revelar uma maior exposição a outras culturas literárias, designadamente inglesa. A imprensa peri- 
ódica bilíngue goesa, quando abordada na sua expressão em língua portuguesa, afasta a primeira hipótese, sem deixar de confirmar a segunda. Esta imprensa merece particular atenção, já que a sua abordagem permitirá questionar e complexificar noções como a de autonomia ou de traduzibilidade dos discursos.

Por outro lado, as polémicas na imprensa periódica evidenciam, sobretudo a partir das primeiras décadas do século 20 , que diversos intelectuais católicos liam publicações em marata e em outras línguas vernáculas indianas. $\mathrm{O}$ ambiente detetável na imprensa obriga-nos a refletir sobre a sua, igualmente suposta, alienação das ideias e conceitos culturais e políticos de tradição indiana tal como surgem veiculados pelas fontes literárias vernáculas. Acresce que a língua inglesa, enquanto língua franca entre a intelectualidade nativa de ambos lados das fronteiras imperiais, ocuparia um lugar de crescente relevância na conversação cultural e política das diversas comunidades e geografias indianas.

Como ainda hoje é evidente, o plurilinguismo integra os patrimónios culturais e a vivência quotidiana de parte significativa dos indianos. No que respeita a literacia na Índia portuguesa, se até tarde as estatísticas oficiais portugueses atendem sobretudo à literacia em português, há que questionar outras fontes para abordar as capacidades linguísticas das elites intelectuais goesas, havendo neste caso que distinguir a capacidade de escrever da capacidade de ler. Cabe neste contexto interrogar se na verdade nos defrontamos com culturas literárias sem veios de comunicação no passado, como nos têm induzido a pensar os discursos nacionalistas, colonialistas e anticolonialistas, na sua ânsia de manipular politicamente os conceitos de assimilação e de genuinidade cultural.

Muito do que fica dito aplica-se igualmente à abordagem da cultura literária concani, hoje oficialmente reconhecida como a língua vernácula goesa. Neste caso, o interesse dialógico é reforçado por nos reportarmos a uma tradição literária que por longo tempo foi assegurada pela intelectualidade oriunda das camadas subalternizadas na sociedade goesa, mas que já vivia a experiência da modernidade a partir dessa posição. Seria a partir dessa experiência que esta intelectualidade buscaria afirmar a sua voz recorrendo a um dos instrumentos mais poderosos de consagração social, política e cultural das elites na modernidade, ou seja a imprensa. Esse programa terá sido largamente frustrado pela indiferença, quando não guerrilha cultural das elites goesas objetivada em olhares elitistas sobre essa produção, como entre outros Rochelle Pinto tem evidenciado, nomeadamente em Between empires (2007), hoje incontornável na historio- 
grafia sobre Goa. Considero nossa responsabilidade democrática procurar fazer sobressair os valores, conceitos e programas culturais e políticos veiculados por esta literatura, mesmo que não expressos nas formas canónicas consagradas pela cultura dominante.

Promover o diálogo entre estas diferentes culturas literárias e culturas políticas não deverá ser colocado ao serviço do apagamento de tensões, diferenças e interesses divergentes que alimentaram e alimentam a criação de memórias conflituantes, mas estou crente em que a desconstrução de discursos consagrados e o esforço de atender às porosidades e aos trânsitos intelectuais, bem como a preocupações comuns, poderão constituir um contributo significativo para o sarar de feridas e para o reconhecimento de um património goês construído na diversidade das suas heranças.

\section{Referências}

BARRETO, Adeodato. Espólio, à guarda de Kalidas Barreto. Papéis soltos (manuscritos). BAYLY, Christopher. Recovering liberties: Indian thought in the age of liberalism and Empire. Cambridge: Cambridge University Press, 2011.

COLLINGWOOD, R. G. The idea of history. Ed. e introd. Jan van der Dussen. 2a ed. rev. Oxford: Clarendon Press, [1946] 1993.

COSTA, Aleixo Manuel da. Dicionário de literatura goesa. s. I. Instituto Cultural de Macau: Fundação Oriente, 1997-2013. 4 v.

COSTA, Aleixo Manuel da. Literatura goesa: apontamentos bio-bibliográficos para a sua história. Lisboa: Agência Geral do Ultramar, 1967.

CUNHA, Carlos Manuel Ferreira da. Geografias da literatura: do nacional ao global. Guimarães: Opera Omnia, 2011.

CUNHA, Vicente de Bragança. Literatura indo-portuguesa. A Índia Portuguesa, 19 abr. 1919, p. 3.

CUNHA, Vicente de Bragança. Literatura indo-portuguesa: figuras e factos. Bombaim: ed. do autor, imp. M. N. Kulkarni, 1926

DEVI, Vimala; SEABRA, Manuel de. A literatura indo-portuguesa. Lisboa: Junta de Investigações do Ultramar, 1971. $2 \mathrm{v}$.

DIAS, Filinto Cristo. Esboço da história da literatura indo-portuguesa. Boletim Eclesiástico da Arquidiocese de Goa, II série, ano 16, n. 6 - ano 20, n. 10, 1957-1961. Disponível em: >http://memoria-africa.ua.pt/<. Acesso em jul.- ago. 2015. 
DIAS, Filinto Cristo. Esboço da história da literatura indo-portuguesa. Goa: Tip. Rangel, 1963.

FERNANDES, Jason Keith. Citizenship experiences of the Goan Catholics. Lisboa: ISCTE, 2013.

LOBO, Sandra Ataíde. O desassossego goês: cultura e política em Goa do Liberalismo ao Acto Colonial. 613 p. e arquivos em DVD. Tese (Doutoramento em História e Teoria das Ideias). Universidade Nova de Lisboa. Lisboa, 2013.

MIRANDA, Eufemiano de Jesus. Literatura indo-portuguesa dos séculos XIX e XX: um estudo de temas principais no contexto sócio-histórico. 246 p. Tese (Doutoramento em Literatura Portuguesa). Goa University, 1995.

MIRANDA, Eufemiano de. Oriente e ocidente na literatura goesa = East and West in Goan literature. Goa: 1556, 2012.

PINTO, Rochelle. Between empires: Print and politics in Goa. Nova Delhi: Oxford University Press, 2007.

RORTY, Richard The decline of redemptive truth and the rise of a literary culture. Disponível em: <http://olincenter.uchicago.edu/pdf/rorty.pdf >. Acesso em 12 ago. 2015.

SILVA, Bernardo Peres da. Diálogo entre um doutor em filosofia e um português da Índia na cidade de Lisboa sobre a constituição política do reino de Portugal, suas vantagens, e meios de mantê-la. Dedicado à mocidade da Índia pelo seu compatriota. Rio de Janeiro: Tip. Nacional, 1832.

SILVA, Cristina Nogueira da. Constitucionalismo e império: a cidadania no ultramar português. Coimbra: Almedina, 2009.

WILLIAMS, Raymond. Culture and society. New York: Anchor Books, [1958] 1960.

WILLIAMS, Raymond. Marxism and literature. New York: Oxford University Press, 1977.

\section{Bibliografia complementar}

BEACH, Christopher. Walt Whitman, literary culture, and the discourse of distinction. Walt Whitman Quaterly Review, v. 12, n. 2, p. 73-85, 1994.

BERNARDES, José Augusto. Cultura literária e formação de professores. In: COLÓQUIO DE DIDÁCTICA LÍNGUA E LITERATURA. 2010, Coimbra. Coimbra: Faculdade de Letras da Universidade de Coimbra, 2010. Separata.

CARVALHO FILHO, Aldir. Sensibilidade, solidariedade, autocriação privada. Rorty e a literatura. Revista Redescrições - Revista on line do GT de Pragmatismo e Filosofia Norte-americana, ano 1, n. esp.: Memória do I Colóquio Internacional Richard Rorty, 2009.

CLARK, Priscilla. Literary culture in France and the United States. American Journal of Sociology, v. 84, n. 5, p. 1057-1077, 1979. 
MACHADO, Rodrigo Martins Corrêa; BARROSO, Suellen Lopes; ALMEIDA, Reselene Vaúna de. A construção da cultura literária brasileira: Gonçalves Dias, o consolidador da identidade nacional na literatura do Brasil. Contemporâneos: Revista de Artes e Humanidades, n. 5, , p. 19-29, nov.-abr. 2010. Disponível em: <http://www.revistacontemporaneos.com.br/n5/pdf/d5 GONCALVES DIAS.pdf>. Acesso em 6 ago. 2015.

MATIAS, André Manuel Ruivo Senos. $O$ ensaio: uma visão crítica da cultura pelo traço literário. Carnets, Cultures littéraires: nouvelles performances et développement, $\mathrm{n}$. spécial, p. 91-103, automne/hiver 2009. Disponível em: <http://carnets.web.ua.pt>. Acesso em 13 ago. 2015.

ORNELLAS, Sandro. Cultura literária contemporânea no Brasil: notas sobre internet, poesia e resistência. Brasiliana - Journal for Brazilian Studies, v. 3, n. 1, p. 69-91, 2014.

QUEIROZ, Luciana Molina. A morte da utopia e a utopia da cultura literária. Uma investigação do pós-moderno a partir da Teoria Crítica. Contextura, n. 5, p. 18-24, 2013. Disponível em: <https://issuu.com/contexturaufmg/docs/revista_contextura_ 5 ed revisada /7 >. Acesso em 24 nov. 2016.

SNOW, C. P. The two cultures and the scientific revolution: the Rede Lecture 1959. New York: Cambridge University Press, 1961. Disponível em: <http://sciencepolicy.colorado.edu/students/envs_5110/snow_1959.pdf>. Acesso em 7 ago. 2015.

Submetido em 25-07-16 Aprovado para publicação em 11-10-16 